\title{
Non-thermal, chemical destruction of PCB from Sydney tar ponds soil extract
}

\author{
A. J. Britten \& S. MacKenzie \\ Cape Breton University, Sydney, Nova Scotia, Canada
}

\begin{abstract}
The Sydney Tar Ponds, in Sydney, Nova Scotia, Canada, contains more than 700,000 tonnes of contaminated sediments including PAH, hydrocarbon compounds, coal tar, PCB, coal dust, and municipal sewage. An important source of contamination are the PCB which cause adverse health affects to humans as well as environmental problems for the surrounding ecosystems through bioaccumulation and resistance to environmental breakdown.

There are various processes for the remediation of contaminated sites. The most commonly used methods include incineration, solvent washing and/or extraction, stabilization/solidification and base catalyzed soil remediation. A recent and more environmentally friendly method for remediation is the "Sonoprocess ${ }^{\mathrm{TM}}$." The claim is that PCB are destroyed in a non-thermal way using a sodium reaction and high frequency vibration to remove the chlorine atoms from the biphenyl. In this study, the process is modified to suit the Tar Ponds matrix and is tested on samples of PCB and PAH contaminated soil from the Tar Ponds. A steel bar (with a chamber containing the contaminated soil, sodium, and solvent attached to the end) is brought to its resonance frequency to destroy harmful contaminants. The energy which is generated is used to vibrate the PCB extract with sodium to break the $\mathrm{C}-\mathrm{Cl}$ bonds. The soil mixture is removed and washed, resulting in clean, safe soil and sodium chloride byproduct. The remaining solution from the extraction has a possibility of being used as a low-grade fuel.

GC-ECD and GC-MS were used to identify and to quantify the compounds present before and after the PCB destruction process. PCB present at $160 \mathrm{mg} / \mathrm{kg}$ in soil were reduced to $<0.25 \mathrm{mg} / \mathrm{kg}$ after extraction treatment. The concentrated oil extract containing $400 \mathrm{mg} / \mathrm{kg}$ PCB had no detectable amount of PCB after the sodium/Sonic process. Chromatograms, mass spectra, and mass spectral interpretation are included in the paper.
\end{abstract}

Keywords: PCB, non-thermal, GC-ECD, GC-MS, tar ponds, sonoprocess ${ }^{T M}$. 


\section{Introduction}

The Sydney Tar Ponds is considered a highly contaminated site. "The Tar Ponds themselves are actually a tidal estuary of thirty-three hectares that contain over 700,000 tonnes of contaminated sediments including Polycyclic Aromatic Hydrocarbons [PAH], hydrocarbon (HC) compounds, coal, tar, Polychlorinated Biphenyls [PCB], coal dust, and municipal sewage" [1]. Environmental analysis of the Tar Ponds site and the degree of contamination showed that levels of PAH in the marine life were 200 times higher than elsewhere in Cape Breton [1].

In the Sydney Tar Ponds, PAH are one of the major contributors to the contamination of the site. PAH are hydrophobic organic compounds with a varying number of aromatic rings fused together and differ in the arrangement of the rings [2-3]. These environmental contaminants are produced through the incomplete combustion process of fossil fuels such as oil and other organic materials including coal and wood [2-5]. The five major sources of PAH in the environment are: heating homes, industrial sources, power plants, incineration, and transportation [5].

PCB are another source of contamination present in the environment including the Sydney Tar Ponds [1]. They differ in chemical structure and toxicity in the number and arrangement of chlorine atoms on the biphenyl structure [6]. The most dangerous PCB are those in the coplanar conformation with chlorine atoms in the para-positions as well as two or more in the meta positions [7]. Coplanar PCB is the conformation where the biphenyl rings share the same plane. The meta- and para-substituted PCB are where the chlorine atoms are attached in the position one and two carbons away from the carbon bonded to the second phenyl ring. The ortho-substituted PCB is where the chlorine atoms are attached to the carbon directly adjacent to that bonded to the second phenyl ring. If chlorine atoms were substituted in the ortho-positions, the steric hindrance of the substituents would eliminate the coplanar conformation. Contaminated soils are of great concern because of the adverse and carcinogenic health effects to humans and animals due to bioaccumulation and their persistent presence in the environment [8-14].

PCB are man-made chemical compounds that were used in industrial practices due to their low vapour pressure, dielectric properties, as well as being non-flammable, chemically and thermodynamically stable [6,13-15]. Sources for the presence of $\mathrm{PCB}$ in the environment include waste sites and landfills, incineration of non-PCB containing waste, improper storage, and high temperature chemical reactions between carbon and chlorine [10-12].

Within the Sydney Tar Ponds site, approximately 5\% (45,000 tonnes) of the total contamination is due to PCB levels greater than 50 parts per million [15]; the internationally accepted threshold for defining material as PCBcontaminated. This $5 \%$ is also contaminated by $\mathrm{PAH}$ compounds. The main source of these contaminants is due to SYSCO (Sydney Steel Corporation), and possibly CN. CN used PCB oil as lubricants within transformers. When the PCB oil was spilled, it went into the ground, leaked into the sewers, and into the North or South ponds. Therefore, high levels of contamination are present at sewage 
outlets and run off sites. Areas in the Sydney Tar Ponds area with the highest levels of PCB include MAID (Municipal Ash and Industrial Disposal Site) $25 \mathrm{ppm}$ and the Coke Ovens area 61ppm [16]. Other areas with significant levels of PCB contamination include NOCO (area North of Coke Ovens), Domtar, Benzol Plant, surface water ways, and Sydney Landfill.

Treatment process for the decontamination of PCB polluted areas can be carried out in a number of ways. The government of Canada favours removal and treatment of contaminated soil and sediment. This solution is often coupled with incineration. Incineration technology for remediation is the most extensively used method today [16]. A drawback to this technique is the high cost of construction and operation. The incinerator must be kept above approximately $540^{\circ} \mathrm{C}$ for long periods of time in order for the process to be effective, complete, and without the release of dioxin or other toxic compounds [9,11,12,15]. Also, the public perception of incineration is not socially acceptable. Incineration is viewed as being unsafe and dangerous for the environment as well as the health and well being of the surrounding residents. If incineration is not applied to a contaminated area, the government of Canada is often in favour of containment, leaving the contamination in place.

Solvent extractions are used where organic solvents can be employed to separate and concentrate contaminants in the solvent $[7,11,15,16]$. This mixture can then be incinerated for remediation. Solvent washing and extraction followed by dechlorination has been shown to be an effective decontamination method $[7,8,16]$. Base catalyzed soil remediation is a promising technique where sodium is added to the soil to breakdown PCB. The result of the system is the treated soil, biphenyl, and sodium chloride [6].

An alternative to incineration and landfill is Sonic Environmental's process. In combination with this technique, the Terra-Kleen solvent extraction process is used to remove the PCBs from the soil in a non-thermal way through the use of a nontoxic solvent [16]. Combined, they are commercially known as the Sonoprocess $^{\mathrm{TM}}$. The non-thermal destruction of PCB and PAH contamination is a socially acceptable method of bioremediation. Solvent extraction is a valuable resource for the removal of PCB, PAH, pesticides, dioxins, DDT, and petroleum products from soil.

In the Sonoprocess, ${ }^{\mathrm{TM}}$ a 2.8 ton steel bar is brought to its resonance frequency using an electromagnetic drive system at each end (Figure 1a). The contaminated soil, sodium, and the solvent are contained within a cell which is attached to the sonic generator (Figure 1b). The energy which is generated from the resonance frequency is captured and used to vibrate and separate the soil particles, releasing the PCB for fragmentation with sodium. The soil mixture is removed and washed, resulting in clean, safe soil and sodium chloride. The remaining solution from the soil extraction has a possibility of being used as a low-grade fuel.

Gas Chromatography (GC) is a widely used method for the analysis of soil extracts [6]. The methodology used in combination with GC was Electron Capture, Flame Ionization, and Mass Spectroscopy [10,13,14,17] including Electron Impact [EI] and Negative/ Positive Ion Chemical Ionization [NCI/ PCI]. 
The Electron Capture Detector (ECD) provides a high degree of sensitivity and selectivity, which is of great value with environmental analysis. ${ }^{18}$ The ECD is a commonly used detector, however, the ECD cannot be used to study all types of chemicals. It is sensitive to compounds with electronegative atoms and functional groups such halogenated compounds, (e.g. PCB) and some PAH. The radioactive source in the detector creates high-energy electrons ( $\beta$ particles) that ionize the detector gas creating thermal electrons. The presence of electrophilic compounds captures these electrons. The remaining electrons are collected at the detector. The ECD provides sensitivity as low as picogram levels and a linear range of approximately $10^{5}$ [18].
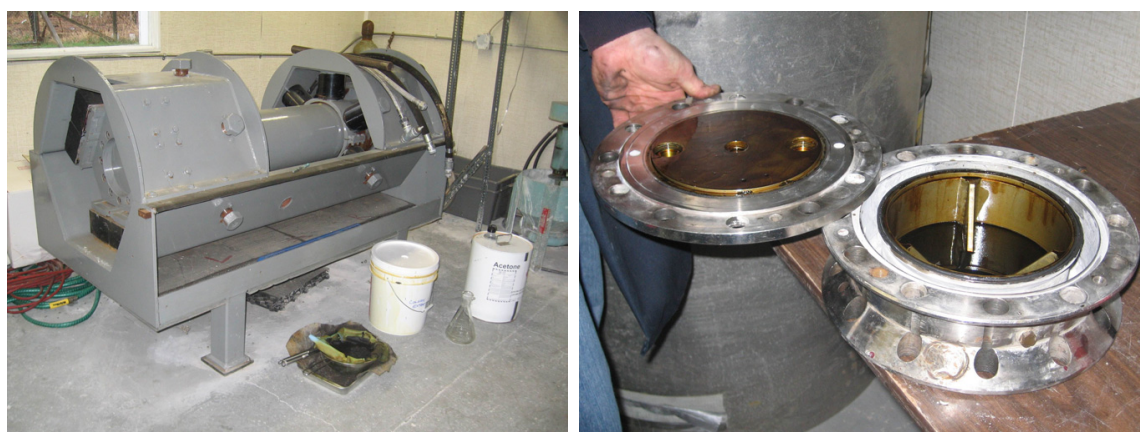

Figure 1: A. steel bar with electromagnetic drive system; b. reaction cell.

The Flame Ionization Detector (FID) is a non-selective detector, which can be applied to environmental analysis.[18] The sample components are burned in a flame of hydrogen and air, producing ions. The ions are collected at the detector to construct the chromatogram of the sample. The FID has the capability of producing chromatograms of all oxidizable carbon containing compounds in the sample. The application of the FID provides a stable detector for analysis with sensitivity of approximately $10^{-10} \mathrm{~g} / \mathrm{s}$ and a linear range of $10^{7}$.

The Mass Spectrometer Detector or Mass Selective Detector (MSD) is a very sensitive detector for low concentration samples. It can be used for both quantitative and qualitative analysis and can be applied to identify unknown substances present in the sample based on GC retention time plus a characteristic spectrum of mass-to-charge ratio versus ion abundance for molecular ions and fragment ions. Ionization of sample components can be achieved in a number of ways including EI, NCI, and PCI. EI ionization often results in a high degree of fragmentation of sample molecules. Chemical Ionization, whether negative or positive, is a 'softer' ionization technique due to lower energy molecule-ion collisions (rather than molecule-electron collision of EI) and therefore results in less fragmentation. Because the molecular ion or pseudo-molecular ion is often of high relative abundance, this technique can be useful especially for analysis of more fragile compounds and can, in some cases, increase selectivity and sensitivity of the components of interest. 


\section{Experimental}

\subsection{Instrumentation}

A Hewlett Packard 6890N Network GC System and 7693B Series Injector from Agilent Technologies. Gas chromatography was combined with FID, ECD and MS (EI, PCI, and NCI). GC column was a J\&K Scientific ICB-5 (30.0m length $\mathrm{x}$ $0.25 \mathrm{~mm}$ internal diameter $\times 0.25 \mu \mathrm{m}$ film thickness). The conditions for each of the methods were varied and the most suitable were applied.

\subsection{Samples}

Samples of contaminated soil were collected by the Sydney Tar Ponds Agency from the Sydney Tar Ponds.

\subsection{Sample preparation}

For the sample preparation of the soil samples collected from the Sydney Tar Ponds (STP), approximately 10 grams of the soil sample was mixed in a beaker with $100 \mathrm{~mL}$ of acetone (Anachemia AC-0150 UN-1090 CAS 67-64-1 $99.5 \% \mathrm{~min}$ ). This solution was spiked with $1000 \mathrm{ppm}$ Chrysene-D12 in acetone and was placed in an ultrasonic bath for a twenty-minute extraction. The soil acetone mix was filtered with Whatman Student Grade Filter Paper $(11 \mathrm{~cm})$ into a filter flask. The above extraction was carried out an additional two times with clean acetone each time. The soil extract was transferred into a $500 \mathrm{~mL}$ separatory funnel. The filter flask was rinsed with benzene to remove left over heavy oil. After extraction the soil was saved for further analysis. The separatory funnel was rinsed with benzene four times to ensure complete transfer of the extract. The Rotovapor was used to remove the acetone and benzene from the extract. The sample was then collected into vials for analysis.

\section{Results and discussion}

The Sydney Tar Ponds soil sample collected and extracted contained high levels PAH as well as PCB contamination. The soil samples were treated and analyzed using various gas chromatographic techniques. The PAH compounds remaining in the treated soil sample from the Sydney Tar Ponds were analyzed using Mass Spectrometry. A standard of PAH compounds was used to identify as many $\mathrm{PAH}$ as possible based on retention time and mass spectral matching.

The Sydney Tar Ponds soil sample was analyzed using GC-ECD. Figure 2 shows the chromatograms of the Sydney Tar Ponds soil extract as well as a PCB standard. The standard shows the peaks, which are PCB compounds present in the contaminated soil. Figure 3 shows the treated soil extract and the PCB standard once again. From these chromatograms, one may observe that the treatment process was successful in the destruction of PCB. Remaining peaks appear to be PCB compounds based on their retention times, however through 


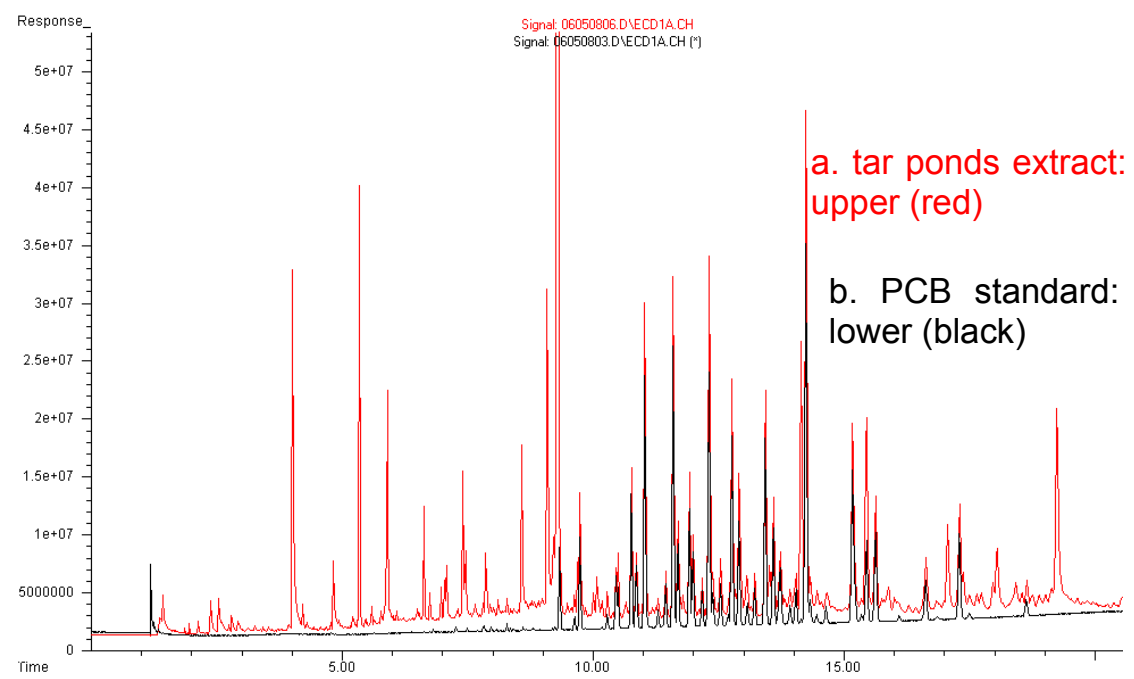

Figure 2: $\quad$ GC-ECD of a. tar ponds extract; b. PCB Standard.

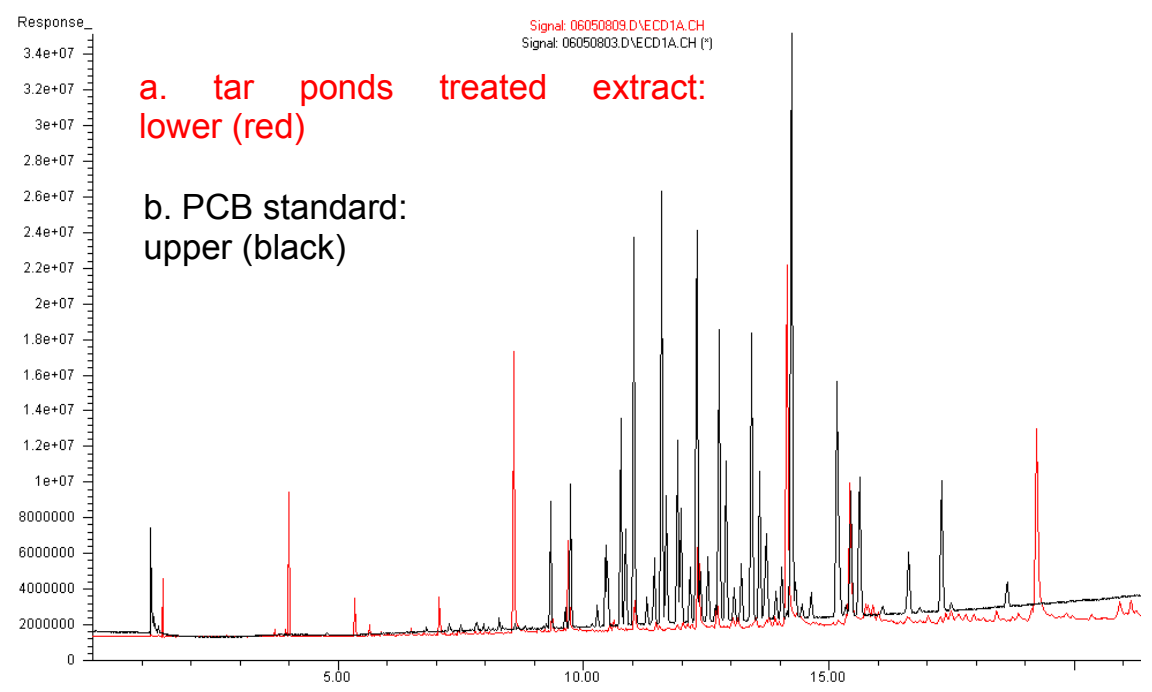

Figure 3: $\quad$ GC-ECD of a. treated tar ponds extract; b. PCB Standard.

analysis with Mass Spectrometry, it was determined that these compounds are not PCB.

PCB are not detected following the treatment process. Therefore, it can be assumed that the PCB compounds have been destroyed during the treatment 
process from the Sydney Tar Ponds soil sample. To confirm the observation of the destruction of the PCB, samples were analyzed by an external Canadian Association for Environmental Analytical Laboratories (CAEAL) accredited lab, which also used GC-ECD. It was confirmed that the PCB had been destroyed during treatment. Prior to treated PCB in soil was $160 \mathrm{mg} / \mathrm{kg}$ and in the concentrated oil, $400 \mathrm{mg} / \mathrm{kg}$. After treatment the concentration of PCB in soil was $<0.25 \mathrm{mg} / \mathrm{kg}$ and was below the GC-ECD detection limit in the oil. For further evidence that the PCB compounds were removed during the treatment process, the treated soil sample was analyzed using NCI, which is an ionization technique with high sensitivity for PCB compounds. From this technique, it shown, again, that PCB are no longer being detected.

Figure 4 has GC-NCI MS chromatograms of Sydney Tar Ponds Soil Extract before and following treatment. The peaks which are PCB compounds are indicated on the figure. These compounds are no longer detected following treatment.

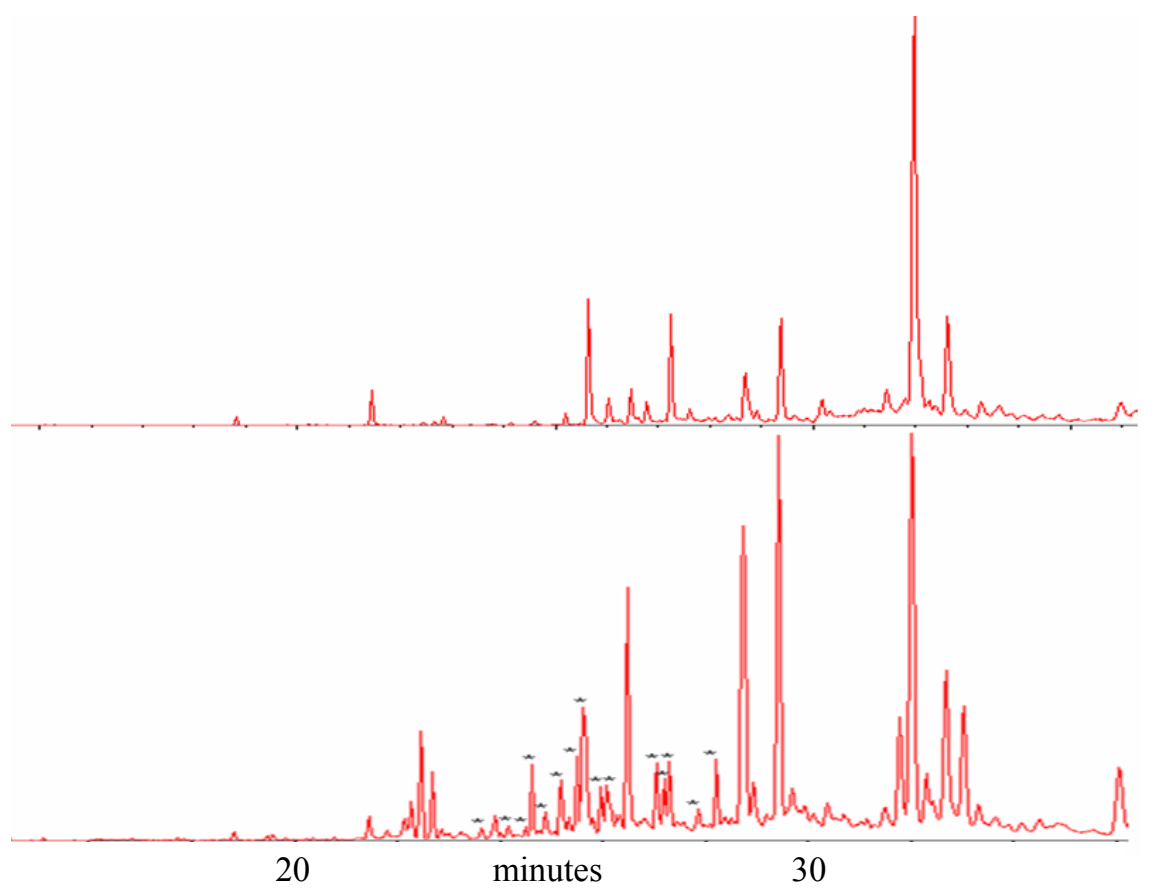

Figure 4: GC-NCI MS chromatograms of a. treated tar ponds extract; $b$. untreated tar ponds extract $\left({ }^{*} \mathrm{PCB}\right.$ in untreated, not present in treated).

In Figure 5, three chromatograms are shown between the significant retention times 20 to 26 minutes. This figure illustrates the differences resulting from the untreated soil sample extract, the effects of using the sep- pack, as well as the treatment of the soil extract sample. One may notice that the Sydney Tar Ponds 
soil extract contains many compounds based on the number of peaks present in the chromatogram. These compounds include PCB, PAH, as well as others, which were not of interest for this particular study. It is the presence of these contaminants, which cause environmental problems for the surrounding ecosystems in addition to adverse health affects to humans and other organisms. It is therefore of great importance to determine as many of these compounds so toxicity of the area can be evaluated.

Also, from Figure 5, one might assume that some compounds remaining in the treated soil sample appear to be PCB due to their retention times as compared to the soil extract. Although these compounds have the same retention times as PCB, based on their mass spectra it was determined that they were not PCB due to the lack of the characteristic isotopic cluster for chorine atoms. Compounds can have the same retention times and not be the same compounds because more than one compound may have eluted from the column at the same time. They were simply not resolved from one other in the untreated soil mass spectrum. The remaining compounds in the treated soil sample were of hydrocarbon compound nature, which are not of concern.

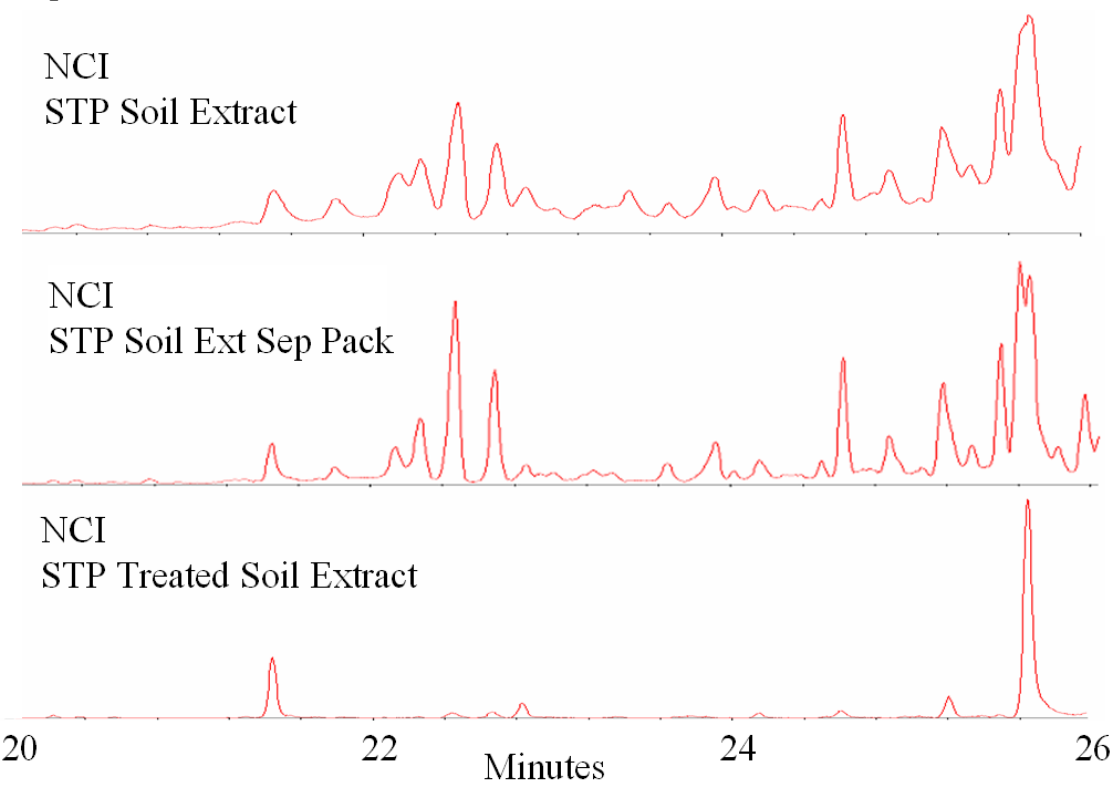

Figure 5: GC-NCI MS chromatograms of a. tar ponds extract; b. tar ponds extract filtered through sep-pak; c. treated tar ponds extract.

Negative Ion Chemical Ionization provides a more selective method of ion separation and results in a chromatogram with increased resolution as compared to PCI (Figure 6). This improvement in the resolution is due to the increased selectivity with NCI. The NCI method of ionization produced sharp, narrow, and 
well-resolved peaks in both the before and after treatment of the soil sample. The resolution of neighbouring peaks is quite low for the PCI method of ionization. Therefore, the preferred method of ionization for environmental analysis is Negative Ion Chemical Ionization.

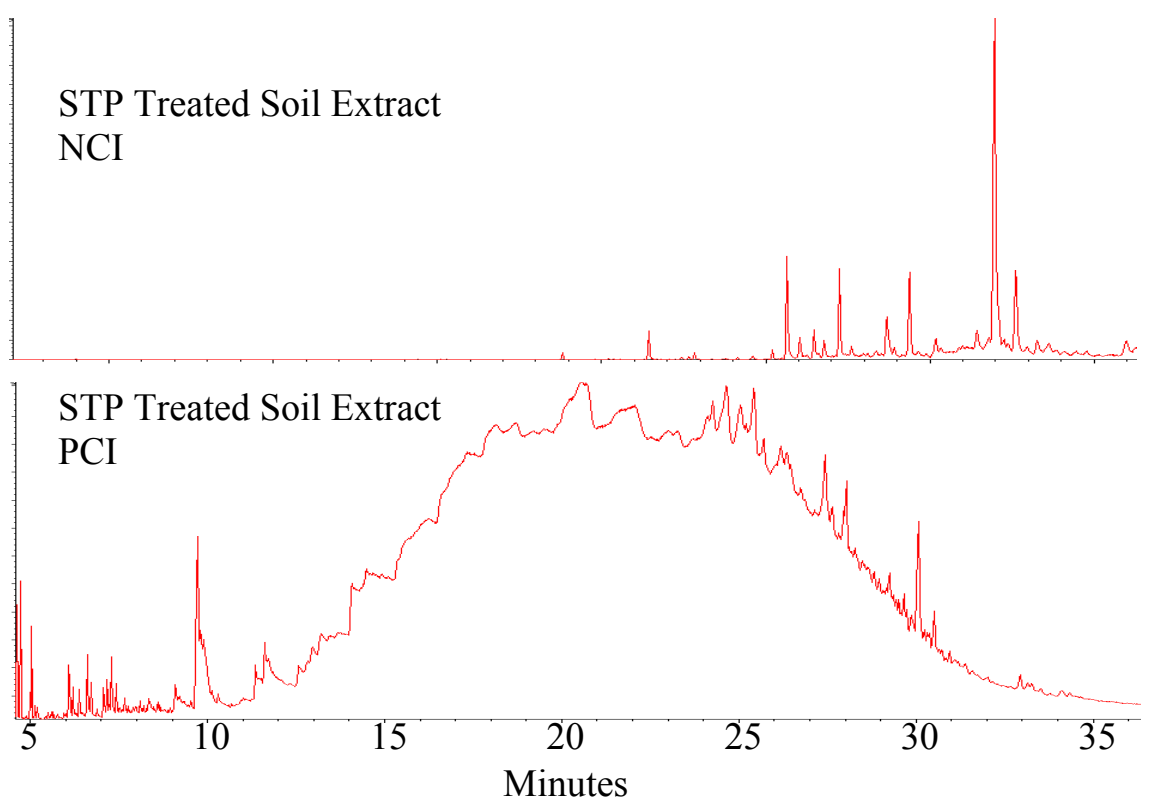

Figure 6: GC-MS of treated tar ponds extract: a. NCI; b. PCI.

From the GC-EI of the treated soil sample, many of the remaining PAH compounds and other aromatic compounds were identified (Figure 7). Some of these compounds included naphthalene, biphenyl, acenaphthene, fluorene, phenanthrene, anthracene, and pyrene. All of the USEPA 16 priority pollutant $\mathrm{PAH}$ were present as well as many higher molecular weight $\mathrm{PAH}$ which are suspected carcinogens.

\section{Conclusion}

The soil samples collected and extracted from the Sydney Tar Ponds contained high levels of contamination including PAH and PCB. The PCB are no longer being detected following the treatment process and therefore it was successful in destroying the PCB. This result has been verified through the use of GC-MS, GC-FID, and GC-ECD as well as by an external lab. The PAH compounds present in the treated Sydney Tar Ponds sample were analyzed GC-MS and identified using a PAH standard mixture for spectral matching and retention time confirmation. 


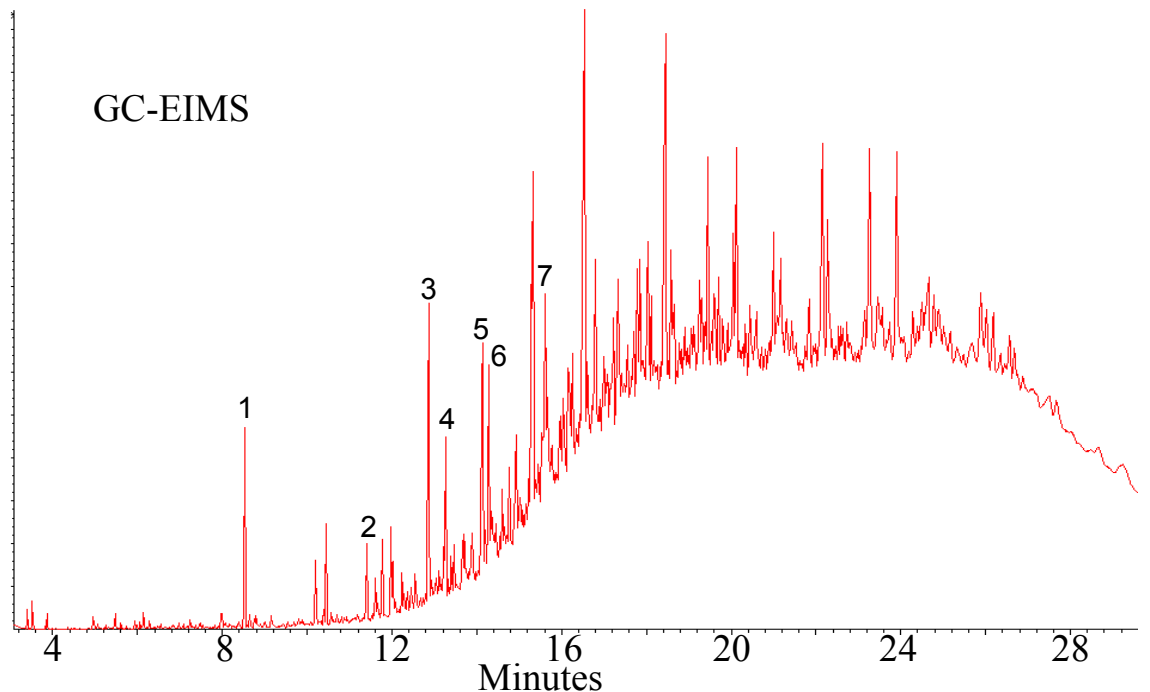

Figure 7: GC-EI MS of treated tar ponds extract. J\&K Scientific ICB-PAH column. 1. naphthalene; 2. biphenyl; 3. acenaphthene; 4. fluorene; 5. phenanthrene; 6 . anthracene; 7 . pyrene.

\section{Acknowledgements}

Financial support was provided from an Office of Research and Academic Institutes, Cape Breton University RAP Grant; the Atlantic Canada Opportunities Agency (ACOA); Enterprise Cape Breton Corporation (ECBC); J\&K Scientific, Inc.; and the Sydney Tar Ponds Agency (STPA). Dr. Rod McElroy's (Sonic Environmental Solutions, Inc.) assistance with the Sonoprocess ${ }^{\mathrm{TM}}$ is greatly appreciated.

\section{References}

[1] Haalboom, B.; Elliott, S.J.; Eyles, J.; Muggah, H., The risk society at work in the Sydney Tar Ponds. Canadian Geographer 2006, 50, 227-241.

[2] Haapea, P.; Tuhkanen, T., Integrated treatment of PAH contaminated soil by soil washing, ozonation and biological treatment. Journal of Hazardous Materials 2006, 136, 224- 250.

[3] Chaspoul, F.; Barban, G.; Gallice, P., Simultaneous GC/MS Analysis of Polycyclic Aromatic Hydrocarbons and their Nitrated Derivatives in Atmospheric Particulate Matter from Workplaces. Polycyclic Aromatic Compounds 2005, 25, 157- 167. 
[4] Yurchenko, S.; Mölder, U., The determination of polycyclic aromatic hydrocarbons in smoked fish by gas chromatography mass spectrometry with positive-ion chemical ionization. Journal of Food Consumption \& Analysis 2005, 18, 857-869.

[5] Bjorseth, A.; Ramdahl, T., eds, Handbook of Polycyclic Aromatic Hydrocarbons: New York, New York, 1985.

[6] Stover, D., Recipe for PCB destruction: Add baking soda. Popular Science 1993, 243, 25.

[7] Majid, A.; Argue, S.; Sparks, B.D., Removal of Aroclor 1016 from contaminated soil by Solvent Extraction Soil Agglomeration Process. Journal of Environmental Engineering \& Science 2002, 1, 59-64.

[8] Chu, W.; Kwan, C.Y., Remediation of contaminated soil by a solvent/ surfactant system. Chemosphere 2003, 53, 9-20.

[9] Seok, J.; Hwang, K., Thermo-chemical destruction of polychlorinated biphenyls (PCBs) in waste insulating oil. Journal of Hazardous Materials 2005, 124, 133-138.

[10] Nobbs, D.; Chipman, G., Contaminated site investigation and remediation of chlorinated aromatic compounds. Separation \& Purification Technology 2003, 31, 37-44.

[11] Wu, W.; Xu, J.; Zhao, H.; Zhang, O.; Liao, S., A practical approach to the degradation of polychlorinated biphenyls in transformer oil. Chemosphere 2005, 60, 944-950.

[12] Van Gerven, T.; Geysen, D.; Vandecasteele, C., Estimation of the contribution of a municipal waste incinerator to the overall emission and human intake of PCBs in Wilrijk, Flanders. Chemosphere 2004, 54, 13031308.

[13] Shimura, M.; Hayakawa, T.; Kyotani, T.; Ushiogi, T.; Kimbara, K., Bioremediation of polychlorinated biphenyl contaminated sludge and ballast. Proceedings of the Institution of Mechanical Engineers Part F Journal of Rail \& Rapid Transit 2003, 217, 285-290.

[14] Kontsas, H.; Pekari, K.; Determination of polychlorinated biphenyls in serum using gas chromatography-mass spectrometry with negative chemical ionization for exposure estimation. Journal of Chromatography $B$ 2003, 791, 117-125.

[15] Magar, V.S., PCB Treatment Alternatives and Research Directions. Journal of Environmental Engineering 2003, 129, 961-965.

[16] Sonic Environmental Solutions, Inc., 2006.

[17] Gurprasad, N.P.; Haidar, N.A.; Manners, T.G., Applications of Negative Ion Chemical Ionication Mass Spectrometry Technique in Environmental Analysis. Communications in Soil Science \& Plant Analysis 2002, 33, 3449-3456.

[18] Karasek, F.W.; Onuska, F.I., Open Tubular Column Gas Chromatography in Environmental Sciences: New York, New York, 1984. 